\section{DISCLAIMER}

This report was prepared as an account of work sponsored-by an agency of the United States Government. Neither the United States Government nor any agency thereof, nor any of their employees, makes any warranty, express or implied, or assumes any legal liability or responsibility for the accuracy, completeness, or usefulness of any information, apparatus, product, or process disclosed, or represents that its use would not infringe privately owned rights. Reference herein to any specific commercial product, process, or service by trade name, trademark manufacturer, or otherwise does not necessarily constitute or imply its endorsement, recom mendation, or favoring by the United States Governtiunt or imply its endorsement, rec and opinions of authors expressed herein do not necest or any agency thereof. The views and opinions of authors expressed herein do not necessarily state or reflect those of the United States Government or any agency thereof.
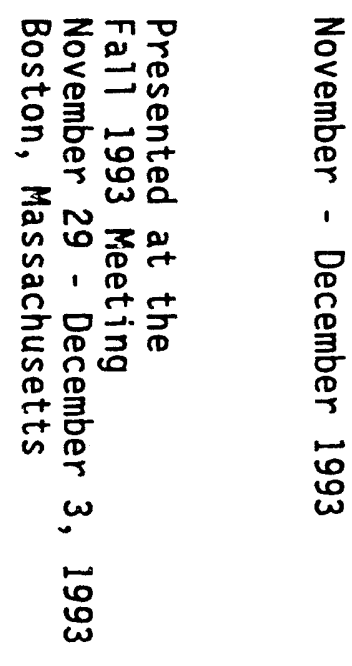


\title{
BIOMIMETIC LITHOGRAPHY AND DEPOSITION KINETICS OF IRON OXYHYDROXIDE THIN FILMS
}

\author{
PETER C. RIEKE* ${ }^{*}$ BARBARA J. TARASEVICH*†, LAURIE L. WOOD*, \\ BRIAN M. MARSH*, GLEN E. FRYXELL*, MARK H. ENGELHARD*, DON R. \\ BAER*, CONNIE M. JOHN ${ }^{\ddagger}$ \\ *Pacific Northwest Laboratory, Materials Sciences Department \& Molecular \\ Science Research Center, Richland, WA 99352 \\ †Dept. of Chemistry, Penn. State Univ., Univ. Park, PA 16802 \\ ‡Shaman Pharmaceuticals, S. San Francisco, CA 94080-4812
}

\section{ABSTRACT}

Heterogeneous nucleation and crystal growth on functionalized organic substrates is a

HECEIVEC MAR 081994

critical step in biological hard tissue formation. Self assembled monolayers can be derivatized with various organic functional groups to mimic the "nucleation proteins" for induction of mineral growth. Studies of nucleation and growth on SAMs can provide a better understanding of biomineralization and can also form the basis of a superior thin film deposition process. We demonstrate that micron-scale, electron and ion beam, lithographic techniques can be used to pattern SAMs with functional organic groups that either inhibit or promote mineral deposition. Patterned films of iron oxyhydroxide were deposited on the areas patterned with nucleation sites. Studies of the deposition kinetic of these films show that indeed the surface induces heterogeneous nucleation and that film formation does not occur via absorption of polymers or colloidal material formed homogeneously in solution. The nucleus interfacial free energy was calculated to be 24 $\mathrm{mJ} / \mathrm{m} 2$ on a SAM surface composed entirely of sulfonate groups.

\section{INTRODUCTION}

Nucleation and growth of minerals at proteins surfaces is a central issue in biological formation of hard tissues [1-4]. The tailored proteins surfaces found in hard tissues confer an ability to localize mineral deposition at specific locations and may also play an important role in the phase of the mineral formed and the orientation of the crystal lattice with respect to the protein surface.

Such control over mineral deposition is of considerable value in formation of ceramics and especially in the deposition of mineral thin films [5-19]. The biomimetic thin film deposition approach makes use of surfaces that mimic the proteins found in nature in order to control the heterogeneous nucleation of the mineral phase. Other thin film deposition technologies, e.g. solgel, plasma vapor, chemical vapor, and slurry techniques, the major role of the surface is in assuring good adhesion and film deposition is essentially a mass transfer limited process. Such is not the case in biomimetic deposition as the surface promotes the phase transformation from an aqueous precursor to the solid mineral phase. The unimportance of the mass transfer step allows the coating of complex shapes such as inside tubes or on gear teeth.

Further, deposition should be spatially confined to only those locations which actively promote mineral deposition. Biomimetic lithography, then, is the patterning of mineral deposition by patterning nucleation sites. Patterned thin films of functional oxide materials (e.g. electrooptical, magnetic, \& piezoelectric materials) can be of great utility in miniaturization of sensors and transducers and subsequent integration into electronic circuits. Biomimetic lithography provides an inexpensive and versatile approach for achieving this objective.

In this paper we demonstrate that control of the deposition of iron oxyhydroxide films is possible and show that classical nucleation theory adapted to heterogeneous nucleation adequately describes the film growth kinetics. We also demonstrate the confinement of deposition to only those locations of a self-assembled monolayer (SAM) surfaces patterned with mineral nucleation sites and the ability to resolve features of about $10 \mu$ in dimension. 
Spatially Resolved Mineral Deposition, P. C. Rieke, et al.

\section{EXPERIMENTAL}

Prior to SAM deposition the silicon wafer strates were cleaned in chloroform, etched in an air plasma, given brief washes in $0.1 \mathrm{M} \mathrm{KOH}$, uen $0.1 \mathrm{M} \mathrm{HNO}_{3}$ and blown dry. Monolayers were deposited on these substrates from a $1 \%$ solution of silane in cyclohexane. The cyclohexane was distilled from calcium hydride prior to use. After 1 hour the samples were removed and rinsed well in chloroform. The films were characterized by ellipsometry and by the advancing contact angle of water.

The octadecyltrichlorosilane and n-vinylheptadecyltrichlorosilane monomers were used to form monolayers. The vinyl terminated SAMs were converted to sulfonate terminated SAMs by exposure to $\mathrm{SO}_{3}$ gas [20]. This was accomplished by venting the vapors from fuming sulfonic acid into a chamber under vacuum into which the samples had been placed. The samples were characterized by XPS and contact angle wetting.

An electron gun from an PHI auger spectrometer was used for etching substrates. The beam was operated at $2 \mathrm{kV}$ at $1 \mu \mathrm{A}$ current for a dosage of $2.4 \mathrm{C} / \mathrm{cm}^{2}$. Gallium ion guns from a, Time-of-Flight Secondary Ion Mass Spectrometer (TOF-SIMS) (Charles Evans \& Associates, Redwood City, CA) and a ion milling machine (FEI, Beaverton, OR) were used to etch the samples. Three bars of some nominal width separated by a distance equal to the width were etched into the surface. The length of each bar was five times the width. The actual dimensions of the bars varied in width from approximately $50 \mu \mathrm{m}$ to approximately $1.0 \mu \mathrm{m}$. Exposures were between approximately $10^{14}$ to $10^{15} \mathrm{atms} / \mathrm{cm}^{2}$.

When necessary electrochemical oxidation was achieved by poising the sample at $1.6 \mathrm{~V}$ versus the saturated calomel electrode (SCE) in $0.1 \mathrm{M} \mathrm{KOH}$. The unetched surface was not affected at this potential; 2.2 to $2.5 \mathrm{~V}$ versus SCE was required to damage the unetched monolayer.

$\mathrm{FeOOH}$ films were deposited from 0.5-4.0 $\mathrm{mM} \mathrm{Fe}\left(\mathrm{NO}_{3}\right)_{3}$ solution in approximately 0.01 $\mathrm{M} \mathrm{HNO}_{3}$. The solution and samples were placed in new $20 \mathrm{ml}$ glass scintillation vials and heated for the appropriate length of time in a water bath thermostated at $70^{\circ} \mathrm{C}$. Films were characterized by ellipsometry (Gaertner) and transmission electron microscopy. The solution speciation code EQ3NR [21] was used to calculate the speciation in solution and the degree of supersaturation with respect to goethite and hematite.

\section{RESULTS AND DISCUSSION}

\section{Spatially Resolved Mineral Deposition}

Fig. 1 is a schematic of the procedure for lithography. First a hydrophobic, OTS, SAM is deposited over the entire substrate. The primary requirement of this layer is the inability to promote heterogeneous nucleation of the inorganic mineral to be deposited. The rate of thin film deposition on this surface was practically negligible compared to more active surfaces.

In the second step ion or electron beams were used to etch the hydrophobic SAM in a desired pattern -- in this case a series of bars or chevrons. We have previously shown that highenergy beams $(>20 \mathrm{kV})$ do not damage the films, and it is possible to image the surfaces by electron microscopy without significant damage [22-23]. These techniques allow rapid and precise writing of complex patterns into SAMs. Patterning of SAMs is possible by other means. For example, deep ultraviolet irradiation can be used to pattern SAMs by photocleavage of terminal groups (24-28). Lopez et al. have used a ball point pen filled with silane (29). Abbot et al. have used fibers to micromachine pattern boundaries on SAMs (30). These schemes might also be adapted for patterned mineralization.

To promote mineralization in the etched areas it is necessary to redeposit or backfill the etched regions with a functionalized or derivatizable silane monomer. However directly after beam etching the silanes will not adhere well to these regions and a brief electrochemical oxidation is required. The electron beam etch has been found to leave a graphitic residue which is easily removed during oxidation [23]. The ion beam etch leaves no residue, as determined by static secondary ion mass spectrometry, but the oxidation renews the silanol population on the surface to 
Spatially Resolved Mineral Deposition, P. C. Rieke, et al.

which the silanes covalently attach. The etched areas can now be backfilled with the desired SAM monomer. To promote FeOOH deposition sulfonate sites were introduced by gaseous sulfonation of a vinyl terminated monomer [20]. Detailed XPS studies of this reaction have shown that essentially $100 \%$ of the vinyl groups undergo reaction and that sulfur is undetectable on the methylterminated regions (31).

The final, almost anti-climatic, step in the scheme of Fig. 1 is deposition of the mineral film, in this case, iron oxyhydroxide $(\mathrm{FeOOH})$. Because the sulfonated portion of the substrates directs nucleation and growth, the resulting film growth is confined to this portion. Other minerals might also be deposited; the key is in designing an appropriate functionalized organic surface.

Scanning electron microscopy (SEM), TOF-SIMS, optical microscopy, and condensation imaging were used to determine the chemical properties of the surface and image these properties on the micron scale. The details of these characterizations will be reported elsewhere [31].

Shown in Fig. 2 is an optical micrographs of FeOOH films deposited on the sulfonated regions of this surface. The bars in Fig. 2 were $50 \times 250 \mu \mathrm{m}$ (Note one of the bars was overwritten twice with a slight offset. The small dark dots in each figure were tiny water spots formed from contaminants during evaporation of previous condensation images.) The brown tint of the iron film was clearly visible against the lighter colored background but is not so readily apparent in this black\&white reproduction. The methyl-terminated regions remained hydrophobic and no optically detectable iron was present. Energy-dispersive spectra of the two regions confirmed that iron was present in easily detectable quantities on the sulfonated region but undetectable on the hydrophobic regions.

The larger bars of Fig. 4 demonstrate the ability to clearly resolve features separated by 50 $\mu \mathrm{m}$. However we have achieved resolutions of approximately $10 \mu$. These dimensions are not state-of-the-art. However our purpose is to describe the basic steps to pattern mineral deposition by using organic surfaces patterned with nucleation sites.

\section{Nucleation and Growth}

The above work has tacitly assumed that deposition of FeOOH occurs by heterogeneous nucleation. This may not be the case and films may be formed by physiorption of polymeric or colloidal species formed in solution. Further film deposition kinetics may be controlled by rate limiting hydrolysis and condensation steps either at the surface or in solution. It is of interest to test if classical nucleation theory can adequately describe the growth behavior of these films.

Calculation of the equilibrium speciation in solution suggests that monomeric iron species $\left(\mathrm{Fe}^{+++}, \mathrm{FeNO}_{3}{ }^{++}, \mathrm{FeOH}^{++}, \mathrm{Fe}(\mathrm{OH})_{2}{ }^{+}\right)$account for $99.99 \%$ of all available iron $[21,32,33]$. Further polymeric species show significant UV-VIS absorption and the solutions were clear upon preparation and remained clear during heating in the thermostated bath. The UV-VIS spectra of the solutions did not change from time of preparation until times long after film deposition had occurred. On occasion precipitation of the solutions did occur, particularly for conditions under which film formation was very slow. Samples from such solutions were eliminated from consideration. From these observation we conclude that only monomeric iron species exist in solution and that film formation does not occur via higher molecular weight species.

Quantitative analysis of XPS spectra show that approximately $100 \%$ of the available vinyl groups are sulfonated during exposure to $\mathrm{SO}_{3}$ gas. Further brief exposure of these surfaces to the mineral deposition solution, iron was physisorbed to the films at a $\mathrm{Fe}^{+++} / \mathrm{SO}^{-}$ratio of approximately 0.5 . The iron was rapidly and irreversibly physisorbed and could not be removed by extended washing. This strong physisorption of iron suggest that film growth may be controlled by hydrolysis and condensation of iron on top of this layer. In this case the initial stages of film growth would be described as a polymerization process rather than as classical nucleation.

Shown in Fig. 3 are film growth rates as measured by ellipsometry for various concentrations of iron. At the highest concentration, no induction period was observed and the deposition rate was linear with time starting from time zero. (note: Approximately 10-15 minutes are required to raise the temperature of the sample solutions from room temperature to $70{ }^{\circ} \mathrm{C}$.) With lower iron concentrations the an increasingly longer induction period was observed with each decrease in iron concentration. After induction the growth rate was essentially constant and did not 
Spatially Resolved Mineral Deposition, P. C. Rieke, et al.

distinctly depend on iron concentration.

Similar experiments as above were conducted for various concentrations of added $\mathrm{HNO}^{3}$ varied from $7.5 \mathrm{mM}$ to $12.5 \mathrm{mM}$ but are not shown in a corresponding plot. These solutions ranged in $\mathrm{pH}$ from approximately 2.15 to 1.95 . As above, increasing induction times were observed for increasing amounts of added acid. And the post induction growth rates did not depend on the amount of added acid.

From the calculations of speciation in solution, the degree of supersaturation of the solutions with respect to formation of goethite can be calculated for each of the above iron and acid concentrations. The values and the induction times can then be compared with classical nucleation theory to determine if this system can be adequately describe by such an approach.

Classical nucleation theory predicts the free energy of formation of a critical nucleus by considering the favorable energy of bulk solid formation and the unfavorable energy of surface area formation $[34,35]$. With appropriate geometric arguments this critical free energy for nucleation $\Delta \mathrm{G}^{*}$, is given by

$$
\Delta G^{*}=\frac{\beta v^{2} \sigma^{3}}{(k T)^{2} \ln (S)^{2}}
$$

Where $\sigma$ is the interfacial surface free energy of the nucleus in contact with the surrounding medium, $v$ is the molecular volume of the solid, and $S$ is the degree of supersaturation, and $\beta$ is a nucleus shape factor. The other constants have their usual meaning. For heterogeneous nucleation $\sigma$ contains a contribution from both the surrounding solution and the interface at which nucleation occurs.

To develop a formalism for the rate of nucleation the critical nucleus is considered a pseudotransition state and it's energy is used in the Arrhenius equation to provide a rate for nucleation. the reciprocal of this has the units of time and is related to the average time for formation of a nucleus. This time is conventionally taken to be equal to the point at which crystal growth begins to dominate nucleation, i.e. the induction time. Taking the log of the equation relating induction time to $\Delta \mathrm{G}^{*}$ gives

$$
\lg \left(t_{\text {ind }}\right)=A+B\left(\frac{\sigma^{3}}{\lg (S)^{2}}\right)
$$

where

$$
\begin{aligned}
& A=\lg \left(\frac{1}{\Omega}\right) \\
& B=\left(\frac{\beta V^{2}}{(k T)^{3} 2.303^{3}}\right)
\end{aligned}
$$

A plot of $\lg$ (tind) versus $1 / \lg (S) 2$ gives the values of $A$ and $B \sigma^{3}$.

A plot of this equation using the calculated values of $S$ and the measured values of $t_{\text {ind }}$ from the experiments described above is shown in Fig. 4. Open circles designate the values for experiments in which iron was varied while filled squares designate those experiments in which added acid was varied. The two sets of experiments extend over slightly different ranges of $\mathrm{S}$ but it is clear that the result of each set is very similar. The linear least squares line drawn through these data has and intercept of 1.059 and slope of .315. The slope gives a value for $\sigma$ of 24.0 $\mathrm{mJ} / \mathrm{m} 2$.

The data are clearly consistent with classical nucleation theory and imply that film deposition occurs by heterogenous nucleation of $\mathrm{FeOOH}$ on sulfonate SAMs. It is also important to note that the analysis of data obtained by variation of both acid and iron concentration agree quite well with each other. While agreement of one set of data with classical nucleation theory could 
Spatially Resolved Mineral Deposition, P. C. Rieke, et al.

have been fortuitous, agreement by variation of two parameters provides strong, convincing evidence that film deposition is indeed controlled by hetcrogeneous nucleation. The value of $\sigma$ is of the correct order of magnitude with the expected value. For example a value of $\sigma$ of 250 or 2.5 $\mathrm{mJ} / \mathrm{m} 2$ would be difficult to rationalize. It should, however be remembered that this value contains contributions from the interfacial free energy between the nucleus and both the solution and SAM. We have not be able to obtain reliable values for the nucleus/solution interfacial free energy by studies of homogeneous nucleation and consequently cannot report on the interfacial free energy of the nucleus/SAM interface.

\section{Conclusions}

The above analysis of the rate data has shown that film growth is very well described by classical nucleation theory. This is not to suggest that hydrolysis and condensation do not occur at the surface but that the key rate limiting step is formation of sufficiently large stable clusters such that further condensation becomes much more favorable than dissolution via hydrolysis of $\mathrm{FeOFe}$ or $\mathrm{FeOHFe}$ bonds.

We also demonstrate that surfaces can be sufficiently selective in their ability to induce nucleation and growth that spatially resolved mineralization is possible by patterning the nucleation sites. While the resolution of our ion beam patterning technique was of the order of $1.0 \mathrm{u}$, the resolution of the mineral deposition step was about $10 \mathrm{u}$. This discrepancy is of considerable interest as it may be related to fundamental properties of nucleation and growth of mineral thin film.

\section{Acknowledgment}

The authors would like to thank Charles Evans and Associates and FEI Corp. for the generous use of their equipment and resources. This research was supported by the U.S. Department of Energy, Office of Basic Energy Sciences and Office of Industrial Technology. Additional funding was received from the National Institute of Health through the Small Business Innovative Research Program (Grant 1 R43 GM47771-01, C. M. John). Pacific Northwest Laboratory is operated for the U.S. Department of Energy by Battelle Memorial Institute under contract DE-AC06-76RLO 1830.

\section{References}

1. Weiner, S.; CRC Crit. Rev. Biochem. 1986, 20, 325.

2. Veis, A.; Sabsay., B.; In Insights into Mineralization, Biomineralization and Biological Metal Accumulation; Westbroek, P.; de Jong, E. W.; Eds.; Reidel, Dordrecht, 1983, pp 273.

3. Biomineralization, Chemical and Biochemical Perspectives; Mann, S.; Webb, J.; Williams, R. J. P., Eds.; VCH, Germany, 1989.

4. Sikes, C. S.; Wheeler, A.P.; Chemical Aspects of Regultion of Mineralization, Univ. of South Alabama Pulbication Service, Mobile, Alabana, 1988.

5. S. Mann, D.D. Archibald, J.M. Didymus, T. Douglas, B.R. Heywood, F. C. Meldrum, N.J. Reeves, Science, 261, 12861993

6. Zhao, X. K.; Fendler, J. H.; J. Phys. Chem 1991, 95, 3716.

7. Landau, E. M.; Levanon, M.; Leiserowitz, L.; Lahav, M.; Sagiv, J.; Nature 1985, 318, 353.

8. Rajam, S.; et al.; J. Chem. Soc., Faraday Trans. 1991, 87, 727.

9. Heywood, B. R.; Rajam, S.; Mann, S.; J. Chem. Soc., Faraday Trans. 1991, 87, 735.

10. Addadi, L.; Moradian, J.; Shay, E.; Maroudas, N. G.; Weiner, S.; Proc. Natl. Acad. Sci. USA 1987, 84, 2732.

11. Ulman, A.; Advanced Materials 1993, 5, 55.

12. Rieke, P. C.; Bentjen, S. B.; Chem. Materials 1993, 5, 43. 
Spatially Resolved Mineral Deposition, P. C. Rieke, et al.

13. Campbell, A. A.; Fryxell, G. E.; Graff, G. L.; Rieke, P. C.; Tarasevich, B. J.; Scanning Microscopy 1993, 7, 423.

14. Bentjen, S. B.; Nelson, D. A.; Tarasevich, B. J.; Rieke, P. C.;J. Applied Polymer Sci. 1992, 44, 965.

15. Rieke, P. C.; Tarasevich, B. J.; Fryxell, G. E.; Bentjen, S. B.; Campbell, A. A.; In Supramolecular Architecture: Synthetic Control in Thin Films and Solids. A.C.S Symposium Series \#499 ; American Chemical Society: Washington, DC. 1992.

16. Heuer, A.; et al.; Science 1992, 255, 1098.

17. Tarasevich, B. J.; Rieke, P. C.; McVay, G. L.; Fryxell, G. E.; Campbell, A. A.; In Chemical Processing of Advanced Materials; J. Wiley \& Sons: New York, 1992.

18. Tarasevich, B. J.; Rieke, P. C. In Materials Synthesis Utilizing Biological Processes; Vol . 174; Rieke, P. C.; Calvert, P. D.; Alper, M.; Eds.; Materials Research Society: Pittsburg, PA, 1988.

19. Rieke, P. C.; Bentjen, S. B.; Tarasevich, B. J.; Autrey, T. S.; Nelson, D. A.; In Materials Synthesis Utilizing Biological Processes, Vol 174, Rieke, P. C.; Calvert, P. D.; Alper, M.; Eds.; Materials Research Society: Pittsburg, PA, 1990.

20. Gilbert, E. E.; Sulfonation and Related Reactions ; Robert E. Krieger Publishing Co: New York, 1977.

21. T. J. Wolery, EQ3NR-A Computer Program for Geochemical Aqueous SpeciationSolubility Calculations, UCRL-MA-110662 pt. III, Lawrence Livermore National Laboratory, 1992

22. Rieke, P. C.; Baer, D. R.; Fryxell, G. E.; Engelhard, M. H.; Porter, M. S.; J. Vacuum Sci. Tech. A . 1993, 11, 2292.

23. Rieke, P. C.; Baer, D. R.; Fryxell, G. E.; Engelhard, M. H.; Porter, M. S.; Submitted to J.. Vacuum Sci. Tech. A.

24. Dulcey, C. S.; et al.; Science 1991, 252, 551.

25. Calvert, J. M.; et al.; Thin Solid Films 1992, 210, 359.

26. Calvert, J. M.; et al.; J. Vac. Sci. Technol. B 1991, 9, 3447.

27. Dressick, W. J.; Dulcey, C. S.; Georger, J. H.; Calvert, J. M.; Chemistry of Materials 1993, $5,148$.

28. Calvert, J. M.; Chen, M. S.; Dulcey, C. S.; Georger, J. H.; Peckerar, M. C.; Schnur, J. M.; Schoen, P. E.; J Electrochem. Soc. 1992, 139, 1677.

29. Lopez, G. P.; Biebuyck, H. A.; Frisbie, C. D.; Whitesides, G. M.; Science 1993, 260 , 647.

30. Abbott, N. L.; Folkers, J. P.; Whitesides, G. M.; Science 1992, 57, 1380.

31. P. C. Rieke, B. J. Tarasevich, L. L. Wood, M. H. engelhard, D.R. Baer, G. E. Fryxell, C. M. John, D. A. Laken, M. C. Jaehnig, Accepted in Langmuir.

32. Schwertman, U.; Cornell, R. M.; Iron Oxides in the Laboratory ; VCH: New York, 1991.

33. C. M. Flynn, Jr., Chem. Revs. 84-1, 31 (1984)

34. A. E. Nielsen, Kinetics of Precipitation, Macmillan Co., New York, 1964.

35. O. Sohnel, J.W. Mullin, J. Coll. Int. Sci., 123, 43 (1988). 
Spatially Resolved Mineral Deposition, P. C. Rieke, et al.

\section{Figure Captions}

Fig. 1 Schematic of the lithography process.

Fig. 2 Optical micrograph of patterned SAM surface after deposition of FeOOH film. Each bar is $50 \times 250 \mu \mathrm{m}$.

Fig. $3 \mathrm{FeOOH}$ film thickness versus time for various concentrations of $\mathrm{Fe}\left(\mathrm{NO}_{3}\right)_{3}$. The $\mathrm{HNO}_{3}$ concnetration was held constant..

Fig. 4 Analysis of induction times for various acid and iron concentrations. 


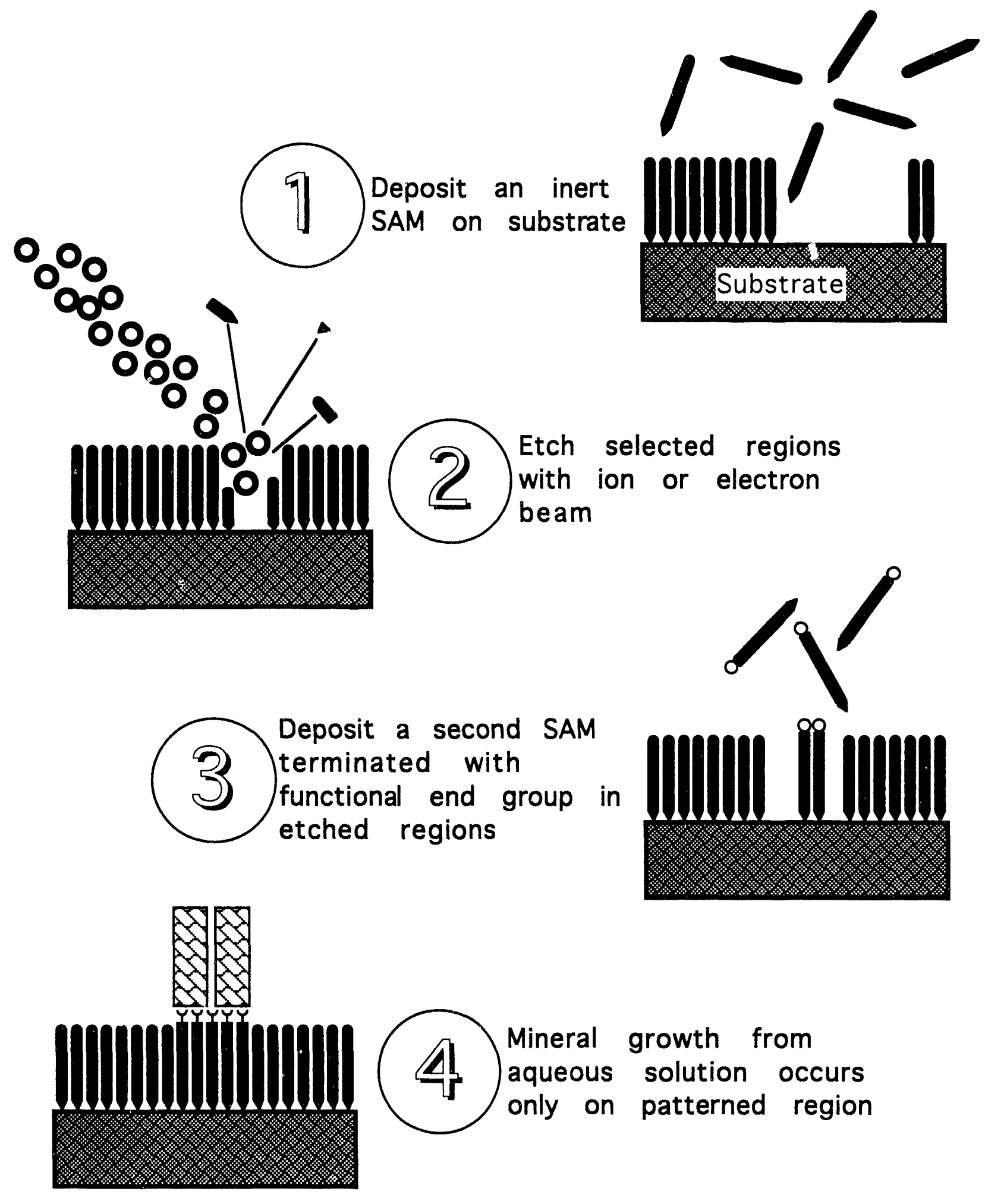

Fig. $1 \mathrm{FeOOH}$ Deposition Kinetics

P.C. Rieke, B.D. Marsh, et al. 

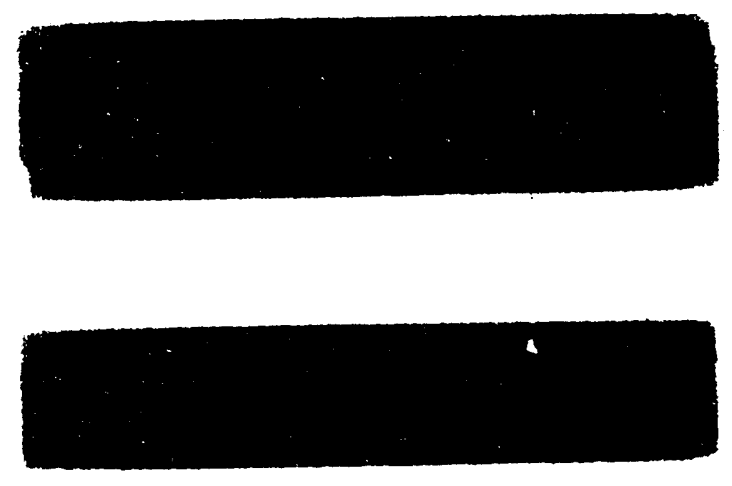

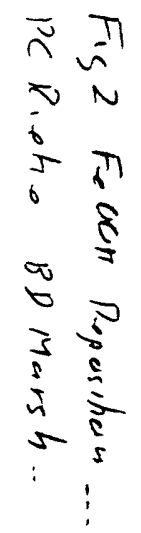




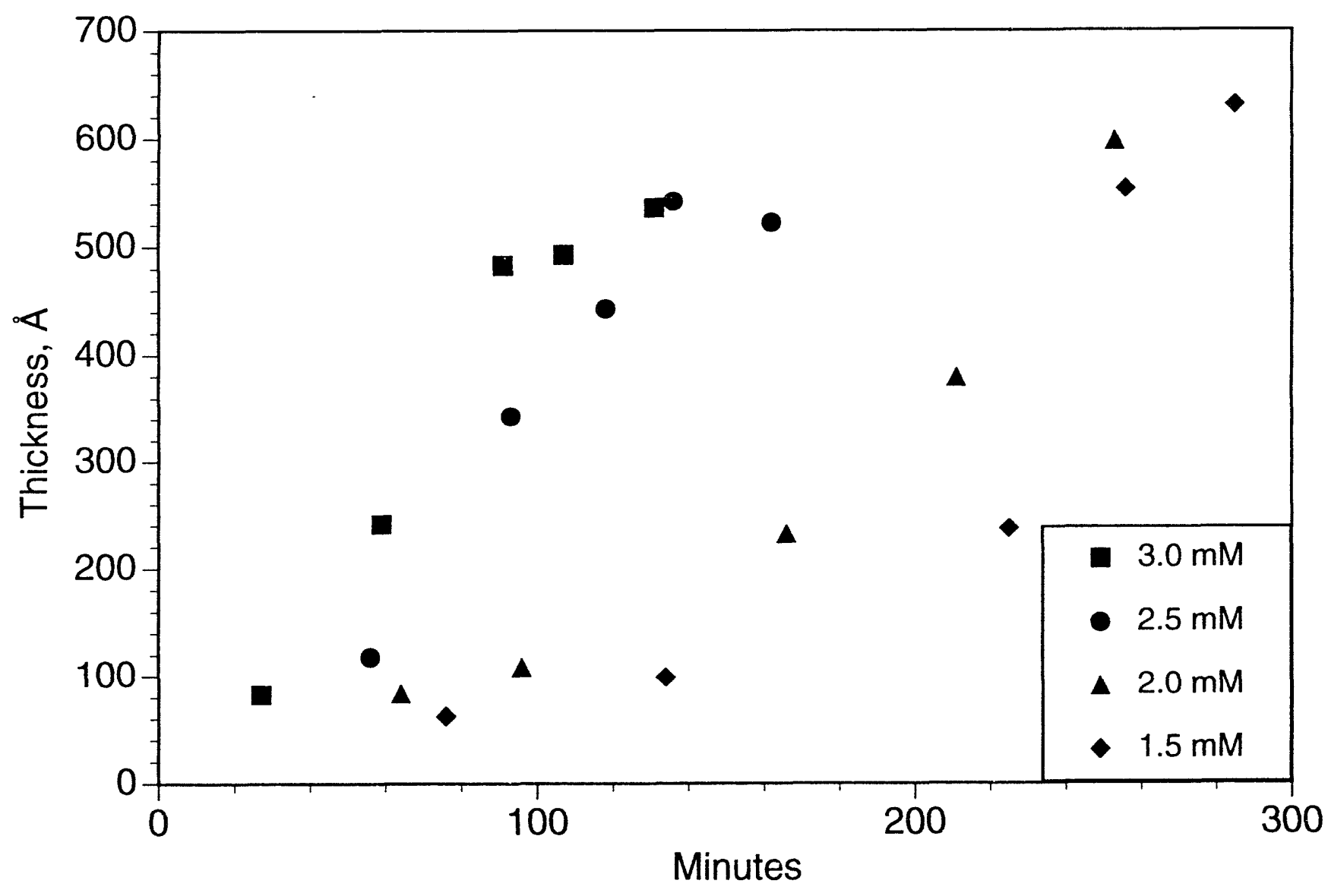

Fig. 3 FeOOH Deposition Kinetics

P. C. Rieke, B. D. Marsh, et al 


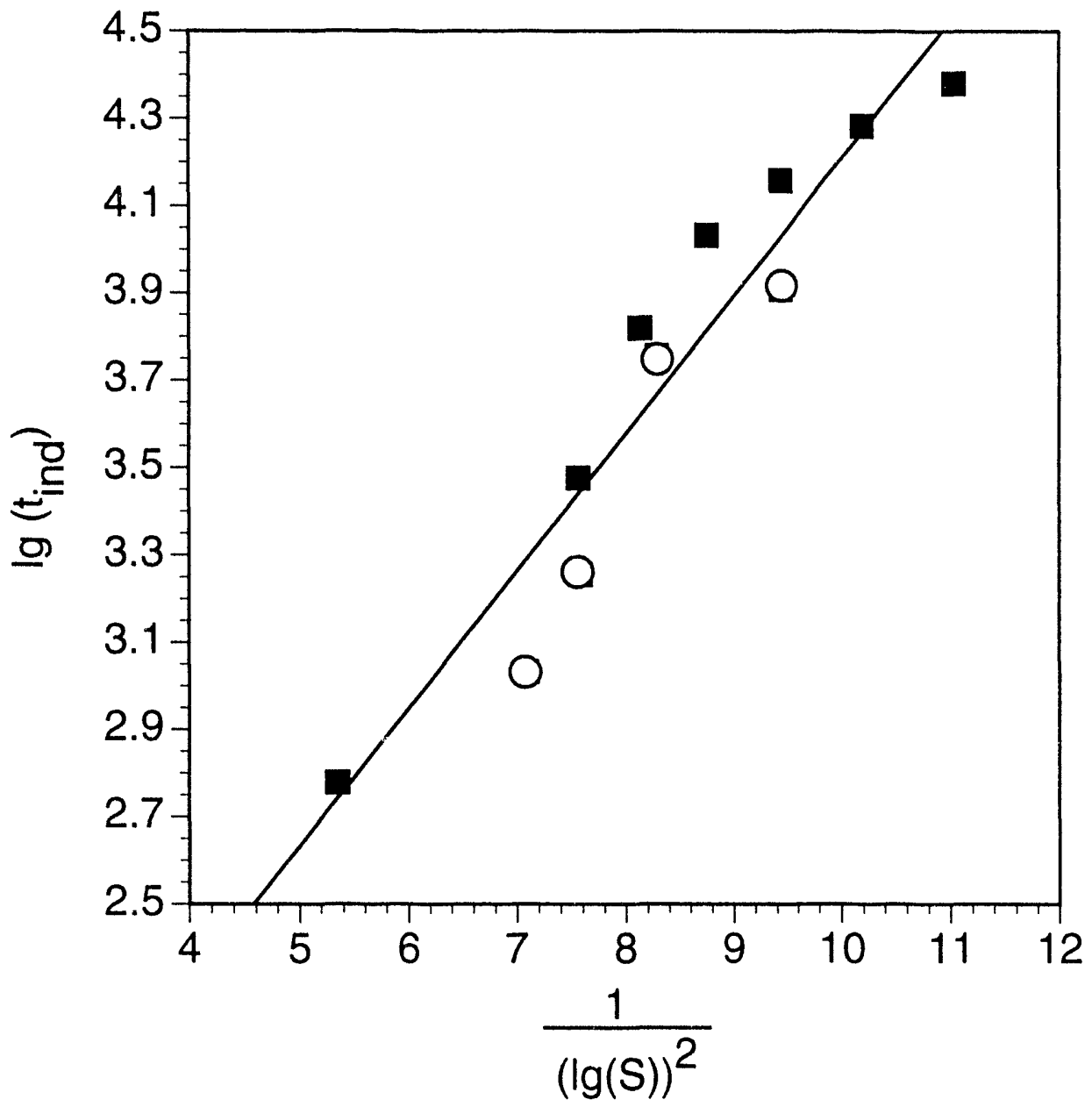

Fig. 4 FeOOH Deposition Kinetics P. C. Rieke, B. D. Marsh, et al 
11
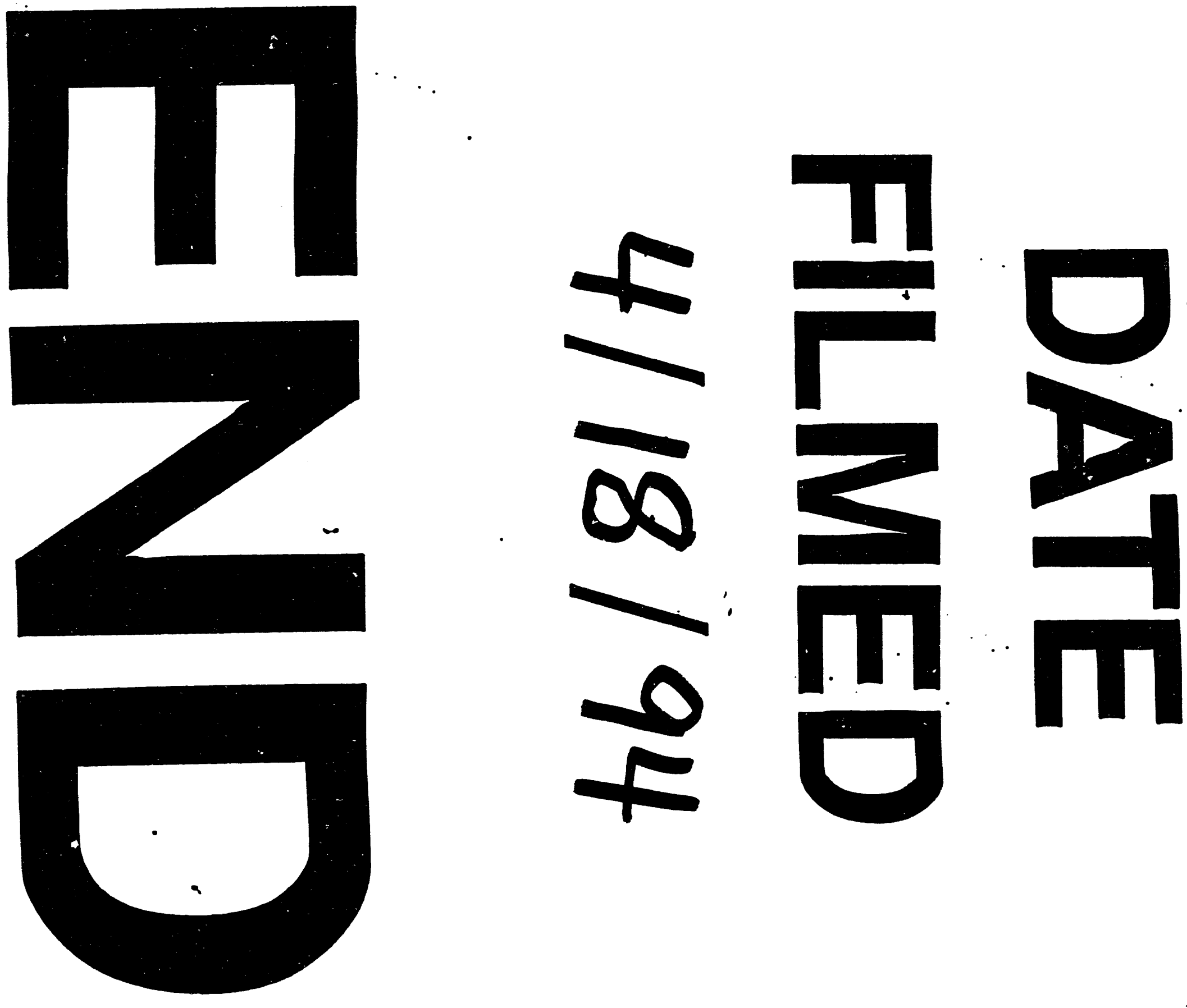
